\title{
Biliary Cyst
}

National Cancer Institute

\section{Source}

National Cancer Institute. Biliary Cyst. NCI Thesaurus. Code C97060.

A cystic dilatation that occurs in any part of the biliary tree. 